\title{
PENSAMIENTO Y ESCRITURA, EL DESAFÍO PARA LOS DOCENTES DE CIENCIAS
}

\section{Thought and writing, challenge for science teachers}

\section{Carlos Enrique Cabrera ${ }^{1}$}

Recibido: 22-2-2017 • Aprobado: 15-4-2017

Escribir es un método para pensar y no es sólo un canal de comunicación.

Paula Carlino

Este ensayo reflexivo aborda la escritura no como una forma mecánica de reproducir el pensamiento, sino como una herramienta epistemológica y cognitiva que lo transforma y fija, potenciando así el aprendizaje. Se expone cómo la escritura per se no genera nuevo conocimiento, pues más bien para que esto se produzca es necesario abordarla como proceso y dividiéndola en etapas recursivas: preescritura, escritura o textualización y revisión. Tras dar cuenta de las tendencias que en las universidades anglosajonas han buscado situar la escritura en el centro mismo del curriculum ("escribir a través del curriculum", "escribir a través de las disciplinas", "alfabetización académica”), se pone de manifiesto la trascendencia que la escritura propia de cada disciplina, manifestándose en géneros discursivos específicos, tiene para los profesores de ciencias, quienes deberían convertirse en verdaderos autores.

1. Profesor del Instituto Tecnológico de Santo Domingo (INTEC), República Dominicana. Dirección electrónica: carlos. cabrera@intec.edu.do

\section{Introducción}

Existen significativas diferencias entre la lengua oral y la lengua escrita. La lengua oral se adquiere de forma natural, mientras que la lengua escrita debemos aprenderla en la escuela, pues implica una técnica. Ampliando lo anterior, en la escuela nos alfabetizan, pero el hecho de que estemos "alfabetizados" no significa que sepamos escribir. Los que así piensan (y aquí entran en buena medida la generalidad de las personas, los profesionales de diferentes campos e incluso, lo que ya es más serio, los profesores de lengua) entienden que la escritura tiene como funciones esenciales transcribir a signos el pensamiento, fijarlo y comunicarlo.

Por las consideraciones anteriores conviene preguntarse lo siguiente: ¿terminan realmente aquí las funciones de la escritura? Como han venido demostrando a lo largo de los últimos treinta años numerosas investigaciones realizadas desde las más diversas disciplinas (lingüística, psicolingüística, lingüística del texto, sociolingüística, pragmática, análisis del discurso, semiótica, lingüística sistémico-funcional, psicología cognitiva, etnografía de la comunicación, etcétera), esto 
de ningún modo es así. Escribir es una actividad de extrema complejidad, que exige un gran esfuerzo personal, intelectual y afectivo, así como la puesta en práctica de numerosos recursos, habilidades y competencias.

En ese ensayo, se procurará mostrar (basados en un modelo psicosociolingüístico de Witte (1992), citado por Juana Marinkovich, 2002), cómo la escritura fija, transcribe a signos, y comunica el pensamiento, nos permite decir lo que ya sabemos, pero además de eso es una poderosa herramienta epistemológica que cambia, transforma y crea conocimiento, incidiendo de forma decisiva en nuestro pensamiento, afinándolo, haciéndolo más claro y preciso, actuando de forma grandemente positiva en nuestro aprendizaje. Como expresa Joaquín Ramos (2009):

No cabe duda de que escribir no es sólo enfrentarse y encontrar solución a una serie de problemas ortográficos, sintácticos, léxicos, de puntuación..., sino que, básicamente, es iniciar un proceso dialéctico (Giroux, 1990), interdisciplinario y epistemológico, con capacidad para generar conocimiento crítico sobre una materia, para desarrollar el pensamiento lógico y, en general, para favorecer los procesos de aprendizaje. (p. 56)

\section{La escritura como proceso}

Entonces, surge la siguiente interrogante: ¡cómo logra la escritura convertirse en una poderosa herramienta epistemológica que cambia nuestro pensar, genera conocimiento, y favorece de forma notable nuestro aprendizaje, como ya afirman hoy los más destacados investigadores en la materia?

Antes que todo, conviene señalar que esta no es una función per se de la escritura, que el simple hecho de escribir no hace de la escritura un factor gnoseológico que genera nuevo conocimiento. Ejemplo de lo anterior es la cantidad de personas que escribe a diario y a lo largo de toda su vida de forma rutinaria, sin que obviamente ocurra ninguna revelación, ningún cambio en su percepción de las cosas, ninguna modificación en su pensamiento ni en su aprendizaje. También encajan aquí aquellos burócratas y funcionarios que a través de sus monótonas jornadas diarias no hacen otra cosa que escribir, pero además muchos de nuestros alumnos en nuestras escuelas y universidades. Como acertadamente señalan Caldera y Bermúdez (2007):

(...) las actividades habituales de lectura y escritura en las instituciones de Educación Superior están caracterizadas por la memorización, reproducción, fragmentación y acumulación del conocimiento. Como resultado de esta realidad, los alumnos presentan poco dominio de las estrategias cognitivas y metacognitivas de comprensión y producción de textos escritos; situación que retrasa el proceso de aprendizaje y disminuye la autonomía del individuo en el uso eficaz del lenguaje como medio de comunicación. (p. 248).

Para que la escritura cumpla con su función gnoseológica y epistemológica y que además incida de manera decisiva en el aprendizaje, afianzándolo y profundizándolo, debe ser abordada de una manera particular. Esto supone un cambio de paradigma, implica concebir la escritura desde otro ángulo muy diferente de aquel estrictamente reproductivo al que muchos alumnos y profesores de escuelas y universidades están aún hoy habituados.

Graham, Harris y Mason (2005), citados por Manuela Álvarez Álvarez, M. Lourdes Villardón Gallego y Concepción Yániz Álvarez de Eulate (2010), "encontraron [en sus investigaciones] que las producciones escritas y las habilidades escritoras pueden mejorar sustancialmente con el aprendizaje de estrategias de planificación y escritura junto con el conocimiento y los procedimientos de 
autorregulación, necesarios para usar estas estrategias efectivamente." (p. 187)

Estas estrategias de planificación y procedimientos de autorregulación nos llevan a hablar entonces de la escritura no como resultado o producto (el texto ya hecho, ya concluido), sino como proceso. La escritura como proceso, asumida por la mayoría de modelos que buscan hoy explicar la producción escrita de textos (véase Juana Marinkovich, 2002, Teodoro Álvarez Angulo y Roberto Ramírez Bravo, 2006), supone la puesta en práctica de estrategias de cognición y de metacognición. Tal como expresa Marta Madrigal Abarca (2008):

Este modelo, denominado Enfoque al Proceso, se centra en las distintas actividades de pensamiento superior, que realiza un autor para componer un escrito, en un período que abarca, desde que se crea una circunstancia social que exige producir un texto, hasta que este [sic] se da por acabado. (p. 129)

La escritura como proceso supone no escribir de un tirón al dictado de la inspiración y dejándose llevar por esta, plasmando en el papel o en la pantalla del ordenador "lo que se sabe", sino que implica acometer la actividad de la escritura dividiéndola en diferentes etapas, cada una de ellas con sus particularidades y especificidades concretas y con sus precisas exigencias técnicas, cognitivas y metacognitivas. Estas etapas se interrelacionan entre sí y tienen sin duda (y esto es muy importante) un claro carácter recursivo.

Según Morles (2003), citado por Caldera y Bermúdez (2007):

La sucesión de etapas [del proceso de escritura] se rige por los principios de recursividad (no es necesario que culmine una etapa u operación para que se suceda la siguiente), concurrencia (dos o más etapas $\mathrm{u}$ operaciones pueden darse al mismo tiempo) e iteratividad (repetición de etapas u operaciones) (p. 252).

Las diferentes etapas que intervienen en el proceso de escritura son: la planificación o preescritura, la textualización o escritura propiamente dicha (también llamada traducción, transcripción) y la revisión y posterior edición y publicación del texto elaborado. Veamos con detenimiento cada una de ellas y sus implicaciones para el conocimiento y el aprendizaje.

\section{Planificación o preescritura}

Esta etapa comprende todo el proceso previo a la escritura del primer borrador del texto. De gran exigencia mental e intelectual, en ella se prefigura o se prevé el texto a desarrollar, se previsualiza en estricta y rigurosa correspondencia con el contexto, buscando la adecuación al medio y a la audiencia. Comprenderá dos sub-etapas, la planeación del escrito, y la organización de las ideas y de la información.

La planeación del escrito supone establecer con claridad y precisión la situación comunicativa que inscribe claramente el texto en su ámbito social, lo que tantas veces se olvida, con las calamitosas consecuencias para la adecuación del texto escrito y, por tanto, para su eficacia comunicativa; lo que nos lleva a establecer: escritor y su papel, destinatario (individual o colectivo) y su papel; propósito o intención comunicativa (informar, convencer o persuadir, instruir o educar, entretener o divertir, prescribir y pronosticar); el tiempo y espacio de la escritura (dónde y cuándo se escribe); el tipo de texto o género (informe, reseña, ensayo, etc.) y el tema del escrito.

Una vez se haya logrado establecer el tema y este se ha delimitado de forma adecuada, se procede a la búsqueda y selección de la información bibliográfica y documental, la cual se plasmará en el texto propio de acuerdo con unas técnicas y unos formatos establecidos, otorgándole a este el carácter 
polifónico de diálogo intertextual propio de los géneros académicos.

Se puede proceder ahora a la segunda sub-etapa, la organización de las ideas y de la información, para lo cual se hará uso de las numerosas técnicas que el escritor tiene a su disposición: mapas conceptuales, sinopsis, listas, diagramas, así como la más elaborada organización de ideas o el esquema de redacción. Este último recurso refleja en su totalidad la estructura formal y la lógico-semántica del texto a elaborar.

Precisar la audiencia, el destinatario del texto a componer, es sin duda de vital relevancia porque implica escribir con "conciencia retórica", lo que tiene consecuencias tanto en la eficacia comunicativa de la composición escrita como en la constitución de la escritura como herramienta epistemológica generadora de nuevos conocimientos. De este modo lo explica Paula Carlino (2003b):

(...) escribir con conciencia retórica lleva a desarrollar y a dar consistencia al propio pensamiento. Problematizar lo escrito desde el enfoque atribuido al destinatario implica cuestionar el conocimiento disponible. Poner en relación los problemas de contenido con los problemas retóricos, intentando ajustar lo que sabe el que escribe a lo que precisaría el lector, es lo que permite transformar el conocimiento de partida (p. 4).

\section{Textualización o escritura}

El subproceso de redacción o textualización consiste en plasmar las ideas sobre el papel o en la pantalla de la computadora en un lenguaje visible; se trata de materializar el pensamiento, de hacerlo observable, concreto y lineal, poniendo en ejecución la competencia lingüística, esto es, utilizando de manera adecuada los aspectos formales de la lengua escrita: la ortografía, la acentuación, los signos de puntuación, la sintaxis y la acertada y pertinente selección de las palabras.
Tal como expresan Rosa Aura Figueroa Meza y José Rafael Simón Pérez (2011): "Este hecho requiere del cumplimiento de distintas exigencias perceptivo-motoras (ejecución gráfica de las letras) y cognitivo-lingüísticas (elección de las palabras, formación de las oraciones, etcétera)." (p. 123). Tan riguroso y complejo proceso se abordará, como veremos a continuación, a través de sucesivos borradores.

\section{La revisión}

El riguroso y complejo proceso de revisión, que tanto exige del escritor, se acometerá, como ya señalábamos, haciendo uso de sucesivos borradores, en número variable, en los que se contemplarán y evaluarán muy diferentes aspectos de forma separada: la estructura textual, de género, de párrafo, etcétera. Se recomienda centrar la atención de forma preferente en la forma y en la estructura del texto, así como en el contenido de este, buscando garantizar, por encima de todo, las que son características esenciales del texto escrito: adecuación, coherencia, cohesión. Por último, ya cuando todo lo antes señalado esté garantizado, se procederá a corregir los aspectos más superficiales de la lengua escrita, la ortografía. Como puntualiza Daniel Cassany (1999):

Lo escrito se asocia exclusivamente con niveles altos de formalidad, con el uso de terminología especializada, y con un cierto grado de complejidad conceptual. De las distintas propiedades lingüísticas de un texto, las más superficiales (ortografía, normativa) son las más valoradas por encima de las más profundas (coherencia, estructura). (p. 56)

\section{Edición final y publicación}

Se tendrán en cuenta aquí, ahora sí, la ortografía, los signos de puntuación, así como la plasmación visual del texto en la página: tipo de letra y tamaño, 
interlineado, sangría, márgenes, títulos y subtítulos, etcétera.

Hasta aquí hemos hablado del proceso de escritura sin circunscribirlo (al menos no de forma clara y precisa, de manera suficientemente explícita) a un ámbito concreto (la escuela primaria o secundaria, la universidad) y a unos actores determinados, con características perfectamente definidas. ¿Cómo se manifiesta la escritura en el ámbito académico de los profesores de ciencia? ¿Cuáles son o deben ser sus relaciones con la escritura y cuáles sus retos ante la misma?

De manera específica, serán abordados los siguientes temas:

a) Los profesores de ciencia y la escritura

b) La especificidad de la escritura según el ámbito del conocimiento

c) La educación académica

Empezamos a escribir como niños, seguimos un proceso, un largo proceso que dura alrededor de diez años y que nos lleva desde la educación primaria a la secundaria, donde la escritura se manifiesta con su particular especificidad; aunque, por lo general y desafortunadamente, la escritura se caracteriza por la copia mecánica, la memorización y la reproducción de saberes. Al llegar a la universidad se nos plantea un duro reto para el que, en verdad, nadie nos ha preparado antes.

La especificidad de la escritura según el campo del conocimiento es un hecho perfectamente constatado. Escribir "bien" o "saber escribir" no supone que podamos hacerlo igual en todos los campos y todas las disciplinas. Cada nivel educativo tendrá sus retos; primaria, secundaria, y el nivel universitario tiene cada uno sus particulares exigencias, que se habrán de ir manifestando con cada vez mayor complejidad, conforme se avance de la licenciatura a la maestría y de esta al doctorado.
Asimismo, cada campo del conocimiento, cada ciencia y cada disciplina imponen su propia cultura escritural y sus propios modos retóricos y discursivos (Carlino, 2003b) que se manifiestan en géneros específicos y concretos, con sus particulares configuraciones estructurales, etcétera. No se puede escribir indistintamente en uno u otro campo. La escritura no es transferible ni "generalizable."

La repercusión de este planteamiento en la metodología de la enseñanza de la escritura en las aulas es realmente grande y de verdadera trascendencia. Implica que la enseñanza de la escritura en las escuelas y en las universidades no es de ninguna manera una tarea exclusiva de un solo profesor, del profesor de lengua; no es una tarea de un curso remedial al inicio de los estudios universitarios, sino que, por el contrario, es una tarea que debe abordar y asumir toda la institución académica, involucrando en la misma a todos los profesores de las diferentes asignaturas (Carlino, 2003a).

Estas tendencias y corrientes se han expresado con particular fuerza en las universidades anglosajonas (norteamericanas e inglesas) a través de lo que se ha denominado "Escribir a través del curriculum" y "Escribir a través de las disciplinas", generando el modelo denominado Alfabetización académica, (Castelló, 2014), surgido en la década de los noventa del pasado siglo.

Paula Carlino (2003a), pionera de esta corriente en América Latina, explica así la alfabetización académica:

Señala el conjunto de nociones y estrategias necesarias para participar en la cultura discursiva de las disciplinas, así como en las actividades de producción y análisis de textos requeridas para aprender en la universidad. Apunta, de esta manera, a las prácticas de lenguaje y pensamiento propias del ámbito académico (p. 410). 
Por su parte López Ferrero (2002), citado por María Marta García Negroni (2009), precisa:

... el dominio de una determinada profesión no es solo de carácter conceptual o lingüístico, sino también retórico: los profesionales saben no solo cómo resolver un problema sino también cómo relacionar su solución empíricamente con casos específicos y cómo presentar su razonamiento y su solución persuasivamente dentro de su ámbito. A medida que un aprendiz se va convirtiendo en experto, lo que adquiere no son simplemente conceptos abstractos o patrones lingüísticos, sino también prácticas retóricas de razonamiento empírico y formas de persuasión propias de la disciplina (p. 47).

\section{A modo de conclusión}

Los profesores de ciencia deben ser capaces de insertarse como miembros de pleno derecho en la comunidad discursiva a la que pertenecen, en la cultura letrada y/o escrita en la que deben estar sólidamente asentados como profesores que no solo enseñan a sus alumnos unos contenidos, sino también unas formas discursivas, la lectura y la composición de unos textos, unos modos de expresarse y de reflexionar específicos y particulares de sus diferentes disciplinas.

Para estar sólidamente asentados en su comunidad académica, los maestros de ciencia deben, dominar no solo los conceptos de sus respectivas ciencias y disciplinas, una metodología particular y la correspondiente bibliografía, sino además los usos discursivos y retóricos y los géneros que les son propios a ellas. Deberían poder hablar y expresarse como hombres y mujeres de ciencia.

Hoy hay un consenso general en afirmar que todo científico, todo doctor competente en una disciplina o en una materia es y debe ser un autor capaz de dialogar, debatir, explicar y convencer a sus iguales (Carrasco Altamirano \& Kent Serna, 2011). Al igual que lo hace un científico, lo debe hacer un profesor de ciencias, aun cuando sea a su particular nivel.

\section{Referencias}

Abarca, M. (2008). La escritura como proceso: metodología para la enseñanza de la expresión escrita en español como segunda lengua. Revista de Filología y Lingüistica de la Universidad de Costa Rica, 34(1), 127-141. Recuperado de http://revistas.ucr.ac.cr/index.php/filyling/article/view/1653

Álvarez Álvarez, M., Gallego Villardon, L. \& de Eulate Álvarez, C. Y. (2010). Influencias de factores sociocognitivos en la calidad de la escritura en los estudiantes universitarios. Educatio Siglo XXI, 28(2), 181-204. Recuperado de http://revistas. um.es/educatio/article/view/112021

Caldera, R. \& Bermúdez, A. (2007). Alfabetización académica: comprensión y producción de textos. Educere, 11(37), 247-255. Recuperado de http:// www.saber.ula.ve/handle/123456789/20149

Carlino, P. (2003a). Alfabetización académica: Un cambio necesario, algunas alternativas posibles. $E d u$ cere, investigación, 6, (20), 409-420. Recuperado de http://media.utp.edu.co/referencias-bibliograficas/uploads/referencias/articulo/246-alfabetizacion-academica-un-cambio-necesario-algunas-alternativas-posiblespdf-d9EbI-articulo.pdf

Carlino, P. (2003b). Pensamiento y lenguaje escrito en universidades estadounidenses y australianas. Propuesta Educativa, 12(26), 22-33. Recuperado de ttp://www.aacademica.org/paula.carlino/112

Carrasco Altamirano, A. C. \& Kent Serna, R. L. (2011). Leer y escribir en el doctorado o el reto de formarse como autor de ciencias. Revista mexicana de investigación educativa, 16(51), 1227-1251. 
Recuperado de http://www.scielo.org.mx/scielo. php?pid $=S 1405-66662011000400010 \&$ script $=s-$ ci_arttext

Castelló, M. (2014). Los retos actuales de la alfabetización académica: estado de la cuestión y últimas investigaciones. Enunciación, 19(2), 346-365. Recuperado de http://revistas.udistrital.edu.co/ojs/ index.php/enunc/article/view/8256/10067

Figueroa Meza, R. A. \& Simón Pérez, J. R. (2011) Composición escrita. Una experiencia con estudiantes del Instituto Pedagógico de Caracas (IPC). Revista de Investigación. 73 (35), 119-147 Recuperado de http://www.scielo.org.ve/pdf/ri/v35n73/ art07.pdf

García Negroni, M. M. (2009). Reformulación parafrástica y no parafrástica y ethos discursivo en la escritura académica en español. Contrastes entre escritura experta y escritura universitaria avanzada. Letras de Hoje, 44(1). Recuperado de http://revistaseletronicas.pucrs.br/ojs/index.php/fale/article/ viewArticle/5652

Marinkovich, J. (2002). Enfoques de proceso en la producción de textos escritos. Revista signos, 35(51-52), 217-230. Recuperado de https://doi. org/10.4067/S0718-09342002005100014

Martínez, J. (2010). La planificación textual y el mejoramiento de la escritura académica. Infancias
Imágenes, 9(2), 35-47. Recuperado de https://dialnet.unirioja.es/servlet/articulo?codigo $=3653126$

Serrano, S. (2014). La lectura, la escritura y el pensamiento. Función epistémica e implicaciones pedagógicas. Lenguaje, 42(1), 97-124. Recuperado de http://www.scielo.org.co/scielo.php?scrip$\mathrm{t}=$ sci_abstract\&pid=S0120-34792014000100005

Nota: este texto se presentó en el quinto Congreso Internacional de Ciencias de la Naturaleza "Competencias Científicas, Pensamiento y Experimentación”, llevado a cabo del 17 al 18 de noviembre de 2016, en el campus Universidad ISA, Santiago de los Caballeros, República Dominicana.

\section{Datos de filiación}

Carlos Enrique Cabrera. Se licenció en Filología Hispánica en la Universidad Autónoma de Madrid (España) y realizó estudios de Bibliotecología y Documentación en instituciones educativas de esa capital europea. Ha publicado: Reflexiones de bolsillo (2002); Tiempos difíciles (2010) -recopilación de ensayos- y Conjuros y otros microcuentos (2013). Es además coautor del libro Español Universitario (Santillana Universitaria, 2006) y de la de información turística: Ciudad Colonial Santo Domingo (Tando Editora, 2011). 